\title{
Scientific Management in Industry
}

FEW documents can give a clearer idea of the ramifications of rationalisation in industry to-day than the annual Report of the International Management Institute (2 Boulevard du Théâtre, Geneva). The Report for 1931, which has recently been issued, although confined to the work and internal administration of the Institute, indicates that in spite of the difficulties created by the economic depression, the interest in scientific management and rationalisation is steadily expanding and the Institute's endeavours to realise the resolutions of the World Economic Conference of 1927 are having important results.

The relation of rationalisation to the economic crisis has attracted much attention, and, in Austria, Dr. Ernst Streeruwitz has issued an important survey of rationalisation in relation to world economy, while the urgent need for economy in many quarters has raised the question of extending rationalisation methods to public administration. The drastic curtailment of public expenditure since 1930 has in many countries taken place on unscientific and haphazard lines, and the reductions are likely, while seriously decreasing the efficiency of the public services concerned, to produce no lasting economies.

Practically no machinery yet exists for the comparative study of public administration, and in most countries the idea of a special planning section continuously engaged in the improvement of great departments of State has yet to be born. Even in large scale industry, knowledge of the principles of organisation and administration is often only superficial. Useful activities are curtailed, while waste which would pay their cost many times over proceeds elsewhere unchecked. Even in the twentieth century, administrators still tend to perform surgical operations with an axe rather than with a scalpel.

The value of the Institute in this field, where widespread research is urgently required, if only as a clearing-house of information, is illustrated by the fact that the Institute receives every month more than 800 periodicals dealing with every phase of rationalisation in every country of industrial importance, and in addition, some hundred books and pamphlets are added monthly to its library. The analysis of these sources of information enables the Institute to avoid the incompleteness which characterises some of the reports included in "The Social Aspects of Rationalisation ", issued by the International Labour Office. ${ }^{1}$
Certain aspects of the work of the Institute, including its association with the World Social Economics Congress at Amsterdam, its own annual discussion conference, and with the Department of Industrial Co-operation, organised for the first time under Section $\mathbf{E}$ at the centenary meeting of the British Association, have already been noted in our columns. In addition to this, various publications dealing with "Scientific Management in a Small Group of Factories", "Railway Systems : their Organisation and Management", etc., have been distributed to members, and work has been carried out for the League of Nations, the International Labour Office, the International Committee for Scientific Management, the International Federation of Consulting Engineers, and the International Chamber of Commerce.

The report demonstrates clearly that there is a widespread and definite desire for an international clearing-house of information on rationalisation. Within its narrow resources, the Institute has greatly increased the efficiency with which it is meeting that need, and the work has been increasingly accomplished by means of subscribed income. The limits of administrative economy have, however, been reached, but it appears almost certain that with continued support from its founders for a further five years, the Institute should become self-supporting so far as its general services are concerned.

The continued services of the Institute are of real importance for the more rational arrangement of the world order in the interests of the general community. As the report rightly observes: "Only by patient research leading to the gradual enlargement of exact knowledge can the world hope to win a more perfect control over the economic organisation of the machine processes which progress in the physical sciences has developed so rapidly during the past century". To persuade men of all nations to adopt a more scientific outlook on economic problems is the fundamental purpose of the Institute, and, forbidden by its statutes to participate in current political controversies, it has sought to facilitate the discovery of the essential facts or laws of the situation upon which alone, and not on political theory or dogma, a modern industrial community can effectively organise its social and economic life.

${ }^{1}$ Studies and Reports, Series B, Economic Conditions, No. 18.

\section{The Idu (Japan) Earthquake of 1930}

$\mathrm{I}^{\mathrm{N}}$ the accompanying map (Fig. 1), the principal faults formed during the Idu earthquake of Nov. 26 are indicated by broken lines, the most important being the Tanna fault, running nearly north and south. In the Tanna tunnel that crosses the fault $525 \mathrm{ft}$. below the surface, the west side was shifted $7 \mathrm{ft}$. $10 \cdot 5 \mathrm{in}$. to the south relatively to the other side, the movement on the surface, however, being distinctly less. In the recent number of the Bulletin of the Earthquake Research Institute (vol. 10, pp. 261-263, 1932), the results obtained from the renewal of the trigonometrical survey are given. The earlier survey was made in 1925-26, the later in Feb.-March 1931, so that the displacements measured may fairly be attributed to the Idu earthquake. They are represented in direction and magnitude by the arrows on the map, and they show that, as in the Californian earthquake of 1906 , both sides were displaced, the west side to the south and the east side to the north.
Near the middle of the Tanna fault, the triangulation point at Daiba on the west side was shifted $28 \mathrm{in}$. to the south, and that at Kurodake on the east side 39 in. to the north, the sum of the two displacements being $5 \mathrm{ft} .7 \mathrm{in}$. It is worthy of notice that during the previous interval, 1884-1925 (including the Kwanto earthquake of 1923), the whole peninsula drifted to the north, the point at Sano being displaced 103 in. to N. $70^{\circ}$ E., that at Daiba 24 in. to N. $7^{\circ}$ W., that at Osaka 46 in. to N. $18^{\circ} \mathrm{E}$., and that at Enasi 48 in. to N. $47^{\circ} \mathrm{E}$.

Some very interesting observations have recently been made by Mr. R. Takahasi on the movements of crust-blocks in the Tanna tunnel (Bull. Earthq. Res. Inst., vol. 9, pp. 435-453; 1931). The object of his measurements was to determine if movements of the crust-blocks continued after the great earthquake, possibly with some of the numerous shocks that followed it. Bench-marks were fixed to 
the concrete wall of the tunnel, in both west and east sections, at intervals of 20 metres, and their displacements were measured on six occasions, the last four series (on Feb. 5-12, March 3-9, April 13-18, and July 18-24, 1931) being the most accurate. Though the changes are very minute, the curves that represent the displacements are remarkably similar. It is interesting also to notice that the principal changes occur in the sections crossed by faults or in which the strata suddenly change in strength, such weak lines forming the boundaries of crust-blocks.

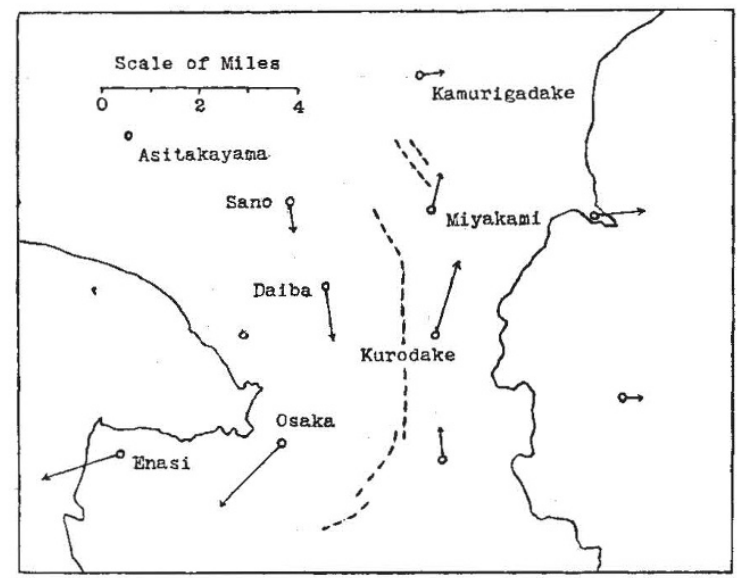

FIG. 1.

It has long been known that an earthquake may be destructive on the surface ground while, in a tunnel below, it mav pass almost, or quite, unnoticed. Mr. N. Nasu has recently provided us with some useful measurements on this subject (Bull. Res. Inst. Earthq., vol. 9, pp. 454-472, 1931). During the Idu earthquake, a few cracks were made in the walls of the Tanna tunnel. Otherwise it was unharmed, though in a village above, 55 per cent of the houses were destroyed. Mr. Nasu placed two similar seismographs, one in the tunnel and the other on the ground above, the rock being of the same nature at both places. During the six months that followed, fourteen strong or moderately strong shocks were recorded.
If the period of the vibrations was less than one second, the amplitude was always more than twice, in one case 4.8 times, as great on the surface as in the tunnel. If, however, the period was as much as 4 or 5 seconds, the amplitudes at both stations were almost exactly equal.

Prof. Imamura and Mr. Kodaira have described some seiches that were observed in the lake of Asino-ko in the northern part of the epicentral area shown in Fig. 1 (Japan J. Astr. Geoph., vol. 9, p. 115-125; 1932). The lake runs nearly north and south and is about $3 \frac{3}{4}$ miles long. The limnograph near the southern end of the lake was thrown out of action by the earthquake at 4.3 A.M., but at 7.20 A.M., when it was repaired, seiches of unusual size were recorded, the amplitude at 9 A.M. being $3.5 \mathrm{in}$. and the period 6.68 min., showing that the seiches were binodal. On several other occasions, seiches were observed, usually on the days preceding swarms of earthquakes, for example, on Nov. 16, 19, and 20, when the numbers of fore-shocks on the following days were 64,530 , and 624, and on Dec. 1, 6, and 9, the numbers of aftershocks on the following days being 240,286 , and 592 . The authors suggest that the seiches were caused by tiltings of the ground, which are known to precede the occurrence of earthquakes.

The tilting of the ground under different conditions is well illustrated in two recent papers (Bull. Earthq. Res. Inst., vol. 10, pp. 130-144 and 145-170;1932). In both cases, the instruments used were horizontal pendulums known as Ishimoto tiltmeters. Mr. W. Inouye describes the movements at the observatory of Mt. Tukuba. The short-period fluctuations, as well as the daily and seasonal variations, are connected with changes in air temperature, an increase in which causes a decrease in the inclination of the mountainside. Earthquakes generally occurred when irregular fluctuations of short period interrupted the long period variations or when the directions of the earth-tilts were changing. Observations of earth-tilts were made at Ito and Kawana in the Idu peninsula from March 19 until July 12, 1930, in connexion with the swarm of earthquakes at Ito during the spring of that year. Mr. R. Takahasi shows that the tilts observed at Kawana must be attributed to changes in the tidal load, though there is some discordance, for which it is difficult to account, between the directions of the observed and calculated tilts.

\section{The British Iron and Steel Industry}

$A^{M O N G}$ the great industries of Britain which are suffering most from the abnormal conditions of trade is the iron and steel industry, regarding which, for various reasons, many erroneous views are held. The basic facts and circumstances of the industry are described by Prof. W. A. Bone in an article in Chemistry and Industry for April 8, entitled "A Survey of the British Iron and Steel Industry, 1913 to 1929 and 1930-31". Referring first to a misleading view expressed in an editorial in the Observer for Dec. 6 last, on the changes in the relative position of the iron industry in the United States, Germany, France, and Great Britain, and the effects of fiscal policy, Prof. Bone says, "The truth is that the changes so indicated have inevitably resulted from natural causes com. bined with human invention and post-War territorial changes, quite independently of any fiscal conditions, and that no change in our fiscal policy can or will prevent the natural course of events".

The supersession of puddled iron by Bessemer and open-hearth steel, the opening up of immense deposits of iron ore in America, the working of the 'basic' process in Germany, the retrocession of Lorraine to
France, and the comparative leanness of the iron ores of Britain are all factors which have led to other countries outstripping us as makers of iron and steel. Smelting and steel manufacture are, however, but two stages in the production of such things as railways, ships, bridges, and motor cars, and the really important question is: Which will pay us best to make, iron and steel or articles from partly imported materials ?

Surveying the last nineteen years, Prof. Bone deals in turn with (1) production in 1913 and 1929 ; (2) a valuation of British iron and steel outputs in 1929 (3) imports of iron and steel raw materials and products in 1913 and 1929 ; (4) exports of iron and steel materials and products; (5) the slump since 1929 ; and concludes with some general considerations. In a series of valuable tables, he gives both the tonnage and the value of imports and exports, and from these it is seen that in 1913 the value of all the iron and steel products and manufactures exported from Great Britain was $£ 111,775,000$, the value of the corresponding imports was $£ 36,175,000$, leaving a balance in our favour of $£ 75,600,000$. The corresponding figures for

No. 3264, VoL. 129] 